\title{
Validação de escala de estratégias de aprendizagem no trabalho entre prefeitos(as) e secretários(as) municipais
}

\author{
Valéria Vieira de Moraes \\ Jairo Eduardo Borges-Andrade \\ Universidade de Brasília
}

\begin{abstract}
Resumo
No mundo do trabalho, espera-se cada vez mais que os indivíduos sejam capazes de aprender a aprender e tomem a iniciativa de seu próprio aprendizado. Nesse contexto, cresce em importância a compreensão dos fatores individuais relacionados à aprendizagem. O presente relato descreve a adaptação e validação de um instrumento de medida de um desses fatores: as estratégias de aprendizagem no trabalho, entendidas como esforços empreendidos pelo indivíduo para realizar a aprendizagem. Partindo de uma escala já validada para o contexto de uma organização do setor bancário, utilizou-se uma amostra composta por 90 prefeitos(as) e 365 secretários(as) municipais, em virtude da intensa demanda por aprendizado que as condições de trabalho dessas pessoas ensejam. Os resultados da análise fatorial indicaram uma estrutura de cinco fatores (reflexão extrínseca e intrínseca, busca de ajuda em material escrito, busca de ajuda interpessoal, aplicação prática e reprodução) consistente com os resultados obtidos com outras amostras.
\end{abstract}

Palavras-chave: estratégias de aprendizagem; aprendizagem no trabalho; setor público; prefeitos; medidas.

\begin{abstract}
Validation of a scale for learning strategies at work among mayors and municipals secretaries. At the workplace, individuals are increasingly expected to be able to learn how to learn and to take the initiative of their own learning process. In this context, understanding of individual factors related to learning gains in importance. This report describes the adaptation and validation of an instrument for the measurement of one of these factors, denominated learning strategies at work, understood as the efforts undertaken by the individual to carry out his or her own learning process in working contexts. Based on a scale already validated in a banking sector organization, the adapted measure was applied to a sample of 90 Mayors and 365 Municipal Secretaries, due to the huge learning demand imposed to them by their working conditions. Results of factor analysis indicated a five factor structure (extrinsic and intrinsic reflection, search for help in written material, search for interpersonal help, practical application and reproduction) that is consistent with the results obtained with other samples.
\end{abstract}

Keywords: learning strategies; workplace learning; public sector; municipal mayors measurement.

$\mathrm{A}$ aprendizagem no trabalho sempre existiu, ainda que a forma prevalente com que ela ocorre tenha variado ao longo do tempo, em grande medida devido a mudanças históricas nos modos de se organizar o trabalho. Por exemplo, a introdução do parcelamento do trabalho e da abordagem científica de gerenciá-lo, característicos da era industrial, foi acompanhada da adoção de métodos e técnicas para treinar o trabalhador no que fosse necessário para o desempenho de suas tarefas da forma exigida pela organização. Assim é que o artesão, que antes aprendia o seu laborioso ofício por meio do contato direto, ao longo de vários anos, com outro artesão mais experiente, se transforma no operário rapidamente treinado para desempenhar uma tarefa simples e específica. Muda a forma de organizar o trabalho e, com ela, a forma prevalente de aprender a executá-lo.
Atualmente, acompanhamos mais uma transformação na natureza do trabalho, conforme salienta Frese (2008). Em um capítulo dedicado ao tema, esse autor identifica dez tendências que apontam nesse sentido: dissolução da unidade de trabalho no espaço e no tempo; mudanças nos conceitos de tarefa e carreira; taxa de inovação acelerada; aumento da complexidade do trabalho; importância da iniciativa pessoal em comparação com a adaptabilidade ao novo local de trabalho; competição global; desenvolvimento de pequenas e grandes unidades; mais trabalho em equipe; redução da supervisão; e, finalmente, aumento da diversidade cultural. Essas tendências assemelham-se aos argumentos apresentados por Sonnentag, Niessen e Ohly (2004) para justificar que o aprendizado se torna cada vez mais relevante, o que permite considerar a hipótese de que também a forma de abordar a aprendizagem nas organizações de trabalho esteja 
passando por alterações.

Vários autores têm encontrado evidências de que a abordagem de aprendizagem que recebeu maior ênfase nas organizações desde a disseminação da proposta tayloristafordista, isto é, a das ações planejadas e estruturadas de treinamento e desenvolvimento, não tem produzido os resultados esperados no contexto contemporâneo (Antonello, 2005; Conlon, 2004; Marsick \& Volpe, 1999). Ao contrário, são justamente aquelas atividades de aprendizagem que acontecem de forma não estruturada as que têm demonstrado contribuir mais significativamente para o desenvolvimento de competências no trabalho (Bierema \& Eraut, 2004; Eraut, 2004; Tynjälä, 2008). Assim, gradativamente, o foco desloca-se para formas de aprendizagem menos estruturadas e iniciadas pelos próprios empregados, com ou sem suporte da organização, para dar conta da complexidade das demandas próprias da era do conhecimento. Existe forte associação entre algumas estratégias de aprendizagem no trabalho e o desenvolvimento de competências gerenciais (Brandão, 2009) e de competências para trabalho estratégico e em equipe (Souza, 2009).

Nesse contexto, ganha relevância o estudo das variáveis envolvidas na aprendizagem que ocorre entrelaçada ao exercício do trabalho, em particular as variáveis individuais, uma vez que esse tipo de aprendizagem é, em grande parte, resultante da iniciativa do próprio indivíduo e o processo nele envolvido está sob controle deste. Para que essa linha de estudos possa ter prosseguimento, é preciso desenvolver medidas confiáveis de estratégias de aprendizagem no trabalho, o construto ao qual se dedica o instrumento cuja validação é aqui relatada e que será detalhada a seguir.

\section{Estratégias de aprendizagem no trabalho}

As estratégias de aprendizagem estão relacionadas aos processos de controle executivo da aprendizagem (Abbad \& Borges-Andrade, 2004). Esses processos são capacidades aprendidas pelo indivíduo ao longo de muito tempo e atuam na focalização da atenção e na manipulação, organização e recuperação da informação, em alguns casos de forma automática e, em outros, sujeitos ao controle voluntário (Pantoja, 2004). Neste último caso, o funcionamento dos referidos processos se baseia na metacognição, que pode ser dividida em dois aspectos distintos: conhecimento sobre os processos cognitivos (sobre si mesmo, sobre a tarefa e sobre o uso de estratégias) e controle do comportamento (planejamento, monitoramento e regulação).

A noção de estratégias de aprendizagem deriva desse segundo aspecto: são capacidades aprendidas de autorregulação do processo de aprendizagem, adquiridas pelo indivíduo ao longo do tempo (Abbad \& Borges-Andrade, 2004). Elas podem também ser definidas como práticas adotadas pelas pessoas visando ajudar a aquisição e o desenvolvimento de conhecimento em qualquer contexto (Holman, Epitropaki, \& Fernie, 2001), ou ainda, segundo Sonnentag et al. (2004), como esforços empreendidos pelo indivíduo para realizar a aprendizagem.

São identificados três aspectos recorrentes nas diferentes definições do conceito presentes na literatura. Primeiro, o fato de que as estratégias de aprendizagem dizem respeito a atividades de processamento de informações que têm por objetivo facilitar a aquisição, retenção, recuperação e uso posterior de novas informações. Segundo, elas também compreendem comportamentos direcionados à aprendizagem e utilização de novos conhecimentos e habilidades. Finalmente, o uso de estratégias de aprendizagem pode contribuir tanto para os processos de aquisição, retenção e recuperação de informações quanto para a transferência a diferentes contextos (Pantoja, 2004). Esta autora destaca ainda que o conjunto de estratégias de aprendizagem utilizado pode variar segundo características do próprio indivíduo ou da tarefa que ele executa.

Em um esforço inicial para organizar o campo, Warr e Allan (1998, citados por Holman et al., 2001) desenvolveram uma taxonomia de estratégias de aprendizagem na qual foram identificadas nove estratégias, agrupadas em três tipos: cognitivas, comportamentais e autorregulatórias. São elas: a) cognitivas (repetição, organização e elaboração); b) comportamentais (procuras de ajuda interpessoal, procura de ajuda em material escrito e aplicação prática); c) autorregulatórias (controles emocional e motivacional e monitoramento da compreensão).

Posteriormente, Holman et al. (2001) realizaram estudo com o objetivo de desenvolver e validar uma escala de estratégias de aprendizagem no contexto de trabalho, no qual obtiveram uma estrutura que corrobora aquela proposta por Warr e Alan (1998) e da qual constam apenas estratégias cognitivas e comportamentais. Essa estrutura (Tabela 1) tem sido usada, com poucas variações, nos estudos mais recentes sobre estratégias de aprendizagem no trabalho.

\section{Medidas de estratégias de aprendizagem no trabalho}

Uma síntese das pesquisas enfocando construção e validação de medidas de estratégias de aprendizagem no trabalho, realizadas no período de 1998 a 2004, foi apresentada por Pantoja (2004). Ela encontra-se reproduzida nos apêndices A1 e A2, com o acréscimo de pesquisas realizadas no período de 2004 a 2009.

O conjunto de pesquisas apresentado corrobora o que aquela autora apontou em 2004: indícios cada vez mais consistentes de uma busca por medidas confiáveis para estudar com maior precisão as estratégias cognitivas e comportamentais de aprendizagem utilizadas por indivíduos no contexto da atuação profissional. No entanto, as amostras de participantes estudadas não privilegiaram dirigentes em postos elevados de organizações, sejam estas públicas ou privadas. Houve dois estudos com gestores, mas não em tais postos.

Nessa perspectiva, o presente trabalho relata a adaptação e validação, com uma amostra de prefeitos(as) e secretários(as) municipais, da escala de estratégias de aprendizagem no trabalho utilizada por Brandão (2009), com gerentes de agências bancárias. A escolha desses participantes para a presente pesquisa se deve ao contexto de trabalho extremamente complexo no qual eles atuam. Dos três níveis de governo que constituem a federação brasileira, o municipal é, sem dúvida, aquele que estabelece uma relação mais direta com a população, na medida em que cabe a ele a execução de grande parte das políticas públicas "visíveis" ao cidadão comum, tais como o calçamento em uma rua, o atendimento no posto de saúde ou a vaga em uma escola de ensino fundamental.

Tal proximidade leva a que os dirigentes desse nível 
Tabela 1

Descrição das estratégias de aprendizagem no trabalho

\begin{tabular}{ll}
\hline \multicolumn{1}{c}{ Estratégia } & \multicolumn{1}{c}{ Descrição } \\
\hline Cognitivas & \\
\hline Reprodução & Procedimento de repetir para si mesmo o material que está sendo aprendido. \\
& Não envolve reflexão sobre o significado do material, nem sua alteração, ou \\
& a visão de como ele poderia estar relacionado com outro material. O ponto \\
& principal é a repetição central ou cópia de informações, usualmente da \\
& mesma forma como foram apresentadas.
\end{tabular}

Reflexão intrínseca $\quad$ Reflexão com vistas a identificar elementos centrais componentes do seu trabalho, bem como criação de esquemas mentais que agrupam e relacionam tais elementos constituintes.

Reflexão extrínseca $\quad$ Reflexão sobre implicações e conexões possíveis entre as diferentes partes componentes do sistema intra e extra-organizacional visando integrar tais informações ao desenvolvimento das atividades profissionais.

\begin{tabular}{lll}
\hline Comportamentais & & \\
\hline Busca de & ajuda & $\begin{array}{l}\text { Procedimentos de busca ativa, por parte do indivíduo, de auxílio de outras } \\
\text { pessoas como pares e professores, para aumentar o seu entendimento sobre } \\
\text { interpessoal }\end{array}$ \\
& o material a ser aprendido, indo além do recebimento rotineiro da instrução.
\end{tabular}

Busca de ajuda em Compreende a pesquisa e localização pelo indivíduo de informações em material escrito documentos, manuais, programas de computador e outras fontes não sociais. Aplicação prática $\quad$ Refere-se às tentativas do aprendiz de colocar em prática os próprios conhecimentos enquanto aprende.

Fonte: Pantoja (2004) e Brandão (2009)

estejam submetidos à cobrança constante de resultados de sua gestão, resultados estes de mais fácil acompanhamento por parte dos munícipes. Novos arranjos de controle social e participação, tais como conselhos e câmaras setoriais, planos diretores e orçamentos participativos, páginas na internet e ouvidorias telefônicas, são, cada vez mais, uma realidade no cenário municipal brasileiro, instrumentalizando e ampliando possibilidades de acompanhamento e fiscalização da atuação governamental nesse nível. A constante cobrança de resultados, portanto, é um dos fatores que contribuem para a configuração de um contexto de grande complexidade com o qual precisam lidar aqueles a quem, por escolha popular ou por indicação do mandatário, cabe a responsabilidade de executar as políticas públicas que constituem o projeto político municipal.

Outro fator gerador de complexidade na atuação de dirigentes municipais é o chamado processo de descentralização ou municipalização, o qual consiste no deslocamento para essa esfera de recursos e responsabilidades que antes competiam aos demais níveis da federação, um movimento que vem se acentuando desde a Constituição de 1988. Além dos fatos já citados, é importante lembrar que os avanços nas tecnologias de informação e comunicação, cujos efeitos sobre a realidade organizacional têm sido amplamente reconhecidos, afetam também as características do trabalho desenvolvido por dirigentes municipais. A necessidade de estar em dia com as inovações afeta as organizações públicas municipais tanto quanto qualquer outro tipo de organização contemporânea.

Assim, é possível supor que o exercício das funções de Prefeito(a) e Secretário(a) Municipal represente, para os indivíduos que têm essa responsabilidade, o grande desafio de dar continuamente as respostas esperadas na execução das políticas que lhes competem, políticas estas cada vez mais sofisticadas e exigentes em termos de conhecimento. Tal desafio aponta para a necessidade de aprender rápida e eficazmente, na medida em que a maioria desses indivíduos, quando assume pela primeira vez um mandato, não teve experiência anterior no exercício da função, nem foi capacitada para isso. A experiência da campanha eleitoral não é suficiente para suprir o aprendizado necessário. As universidades brasileiras, para aqueles ou aquelas que tiveram oportunidade de acesso a elas, oferecem uma formação disciplinar segmentada que não reflete a complexidade da administração pública e não há, na maioria das vezes, oferta de cursos visando à formação para essas funções (Matus, 1996). Não há também, nesse caso, a oportunidade de aprender no dia-a-dia com pessoas experientes, o que obriga essas pessoas a tomarem a iniciativa de sua própria aprendizagem.

O quadro até aqui exposto fundamenta, por um lado, a decisão de se buscar consolidar a confiabilidade da medida de estratégias de aprendizagem no trabalho utilizada, e, por outro, a decisão de trabalhar, para essa finalidade, com um público cuja realidade de trabalho exige intensa utilização das referidas estratégias. Este público raramente foi objeto de investigação em psicologia do trabalho e das organizações. As próximas seções desse texto descrevem as características do estudo, os resultados obtidos, encerrando com uma discussão sobre estes últimos e as perspectivas de pesquisa que deles podem decorrer.

\section{Método}

\section{Participantes}

A amostra teve caráter não aleatório em função de algumas contingências relativas à população estudada e à própria pesquisa. A primeira contingência refere-se à dificuldade de acesso às equipes de dirigentes municipais, que exigiu a busca de apoio preliminar com a direção nacional de um partido de modo a credenciar o pedido de agenda a ser feito. Isto levou à restrição de municípios participantes àqueles cujo(a) prefeito(a) fosse filiado 
ao partido em questão. É importante notar que tal restrição não se estendeu ao restante da equipe dirigente, a qual, na maioria dos casos, era multipartidária. A segunda contingência referiu-se a restrições orçamentárias da própria pesquisa, cujos recursos não seriam suficientes para realizar as visitas necessárias à obtenção de uma amostra representativa dos mais de 5.500 municípios brasileiros, uma vez que a aplicação dos questionários foi feita presencialmente para garantir a confiabilidade dos dados e o seu retorno.

Assim, buscou-se alcançar o número de participantes necessário para atender as exigências da validação estatística, ao mesmo tempo em que, dadas as restrições já expostas, buscouse contemplar casos das diversas regiões do país, resultando em uma amostra de 455 indivíduos, cujas características estão descritas na Tabela 2. O universo, neste caso, é composto de 5.564 prefeitos(as), correspondendo ao número de municípios brasileiros, e um número indeterminado de secretários(as), uma vez que não existe uma padronização que determine a estrutura do executivo municipal para todas as localidades.

\begin{tabular}{|c|c|c|}
\hline \multicolumn{3}{|c|}{ Composição da amostra segundo essas características } \\
\hline Gênero & 324 homens & 131 mulheres \\
\hline Função & 90 Prefeitos(as) & 365 Secretários(as) \\
\hline Idade & Média $=43,78$ & $D P=8,24$ \\
\hline Escolaridade & $\begin{array}{l}\text { Ensino Fundamental = 3,3\% } \\
\text { Ensino Médio }=17,58 \% \\
\text { Graduação }=29,12 \%\end{array}$ & $\begin{array}{l}\text { Especialização }=38,46 \% \\
\text { Mestrado }=9,34 \% \\
\text { Doutorado }=2,20 \%\end{array}$ \\
\hline
\end{tabular}

\section{Instrumento}

O questionário validado por Brandão (2009) possui 28 itens distribuídos entre 5 fatores, respondidos em uma escala de 11 pontos do tipo Likert (' 0 ' = Nunca faço a ' 10 ' = Sempre faço). A decisão por sua adaptação baseou-se no fato de que esse autor estudou as estratégias de aprendizagem no trabalho de gestores do setor bancário, um contexto com características distintas daquelas dos participantes da presente pesquisa. Foi necessário adaptar o vocabulário para representar mais precisamente o contexto em que atuam prefeitos(as) e secretários(as) municipais, especialmente considerando que essas pessoas exercem funções no mais alto nível de decisão das organizações em que atuam, não estando, portanto, submetidas a um contexto de gestão determinado por terceiros acima deles numa hierarquia organizacional. A eles compete cumprir o programa de governo, em cuja formulação eles tomaram parte, sendo obrigatório apenas que o referido programa esteja de acordo com as normas legais vigentes. Mesmo quando discutem as questões centrais do governo, nas instâncias do partido ou com suas bases, fazem-no em condições de igualdade e é reservada a eles a discricionariedade de tomar as decisões organizacionais, ainda que se considere desejável que essas decisões sejam oriundas de um consenso político.

Dois itens foram retirados, pois não se referiam a questões pertinentes ao contexto a ser estudado ("Consultando informações na intranet da organização..." e "Peço ajuda aos meus colegas de equipe..."). Os demais itens foram modificados para retratar essa realidade. Por exemplo, o item "Consulto colegas de trabalho mais experientes quando tenho dúvidas sobre algum assunto relacionado ao meu trabalho", da escala original, passou a ser "Converso com outros dirigentes mais experientes quando tenho dúvidas sobre algum assunto relacionado ao exercício da minha função" na escala adaptada.

\section{Procedimentos de coleta e análise dos dados}

Os questionários foram aplicados in loco, no mês de agosto de 2009, a 187 indivíduos do primeiro escalão das prefeituras de 41 municípios. Em dezembro, foram preenchidos mais 33 questionários por indivíduos que participavam de um seminário promovido pelo partido, em Brasília, perfazendo um total de 220 casos de pessoas em final de mandato. As análises realizadas com este primeiro conjunto de dados não foram muito confiáveis (indicadores inferiores aos obtidos por Brandão (2009) e aquém do adequado no caso dos fatores $2 \mathrm{e} 5$, com alfas de 0,50 e 0,58 ), o que levou à decisão de incorporar novo conjunto de dados.

Assim, durante a primeira quinzena de janeiro do ano seguinte, foram aplicados in loco mais 235 questionários a indivíduos no início de seu primeiro mandato, perfazendo a amostra de 455 casos. Todos os questionários foram preenchidos individualmente, mesmo nos casos in loco, nos quais a aplicação foi coletiva. A entrega dos questionários era precedida de uma breve explicação sobre a pesquisa e da assinatura do termo de consentimento livre e esclarecido.

Os dados obtidos com a aplicação dos questionários foram submetidos a análises estatísticas descritivas e de cunho exploratório, seguindo as recomendações de Hair Jr., Anderson, Tatham e Black (2005). Em seguida, os dados foram submetidos à análise de componentes principais ( $\mathrm{PC}$ ), à análise fatorial (PAF, rotação oblíqua, Promax), bem como à análise de consistência interna (alfa de Cronbach), a fim de examinar a estrutura empírica do instrumento, validar estatisticamente o conteúdo e julgar sua confiabilidade.

\section{Resultados}

A análise dos histogramas das variáveis e dos índices de skewness e kurtosis revelou a ausência de distribuição normal em todas as variáveis. Ainda assim, tendo em vista que a análise fatorial é razoavelmente robusta a violações do pressuposto da normalidade, particularmente em amostras com mais de 200 casos (Hair Jr. et al., 2005), optou-se pela realização dos procedimentos subsequentes com os dados originais, sem realizar transformações. A análise das correlações entre as variáveis indicou também a ausência de multicolinearidade. A análise da matriz de covariância apresentou a existência de valores superiores a $0,30 \mathrm{em}$ mais de $50 \%$, indicando sua fatorabilidade e o índice de Kaiser-Meyer-Olkin $(K M O)$ de 0,93 apontou a adequação da amostra. Esses indicadores fundamentaram as condições para a realização da análise fatorial pretendida.

A comparação entre valores próprios empíricos e aleatórios (Tabela 3), resultante da análise paralela (Ranigen), indicou a pertinência da extração de até quatro fatores e a análise do scree plot (Figura 1) indicou a possibilidade de até seis fatores. Por sua vez, a validação dessa escala feita por Brandão (2009) resultou em uma estrutura de cinco fatores (Reflexão Extrínseca 
e Intrínseca, Busca de Ajuda Interpessoal, Busca de Ajuda em Material Escrito, Reprodução e Aplicação Prática) com coeficientes alfas de Cronbach variando entre 0,79 e 0,92, KMO $=0,89$ e variância total explicada de $62,3 \%$.

Tabela 3

Valores próprios aleatórios e empíricos dos dez primeiros componentes

\begin{tabular}{ccc}
\hline Componentes & $\begin{array}{c}\text { Valores } \\
\text { próprios } \\
\text { aleatórios }\end{array}$ & $\begin{array}{c}\text { Valores } \\
\text { próprios } \\
\text { empíricos }\end{array}$ \\
\hline 1 & 1,69 & 6,79 \\
2 & 1,58 & 2,81 \\
3 & 1,50 & 2,15 \\
4 & 1,43 & 1,69 \\
5 & 1,37 & 1,34 \\
6 & 1,31 & 1,20 \\
7 & 1,26 & 1,17 \\
8 & 1,16 & 1,02 \\
9 & 1,11 & 0,87 \\
10 & 1,07 & 0,70 \\
\hline
\end{tabular}

A exemplo dos resultados das análises e da validação de Brandão (2009), foi realizada análise dos eixos principais (PAF) com rotação Promax, com a extração de quatro, cinco e seis fatores. A solução com cinco fatores, variância total explicada de $59,70 \%$, foi a que obteve os melhores índices de confiabilidade nos fatores e cargas fatoriais dos itens. Além disso, os fatores extraídos foram os que apresentaram melhor congruência com os achados tomados como referência na pesquisa (Brandão, 2009).

Quando do teste das diferentes extrações, na solução com seis fatores, o sexto fator consistiu de dois itens que iniciavam com a palavra "não", invertendo o sentido da frase ("Não questiono normas e procedimentos relativos ao exercício da minha função" e "Não reflito sobre a relação entre a minha função e os objetivos do governo"). Estes itens foram comentados pelos respondentes repetidas vezes como sendo itens de difícil compreensão, uma vez que a consideração das âncoras da escala exigia refletir sobre duas negativas, a da âncora ("nunca faço") e a do item (não reflito). Como a estrutura assim obtida era semelhante àquela de cinco fatores, excluindo-se o sexto fator, essa consideração somou-se às demais apontadas para justificar a adoção da solução com cinco fatores com a exclusão dos dois itens com a redação negativa.

A tabela 4 apresenta os fatores identificados, os índices de confiabilidade obtidos em cada um deles, bem como os itens e suas cargas fatoriais. Quatro itens apresentaram cargas fatoriais maiores que 0,30 em mais de um fator, porém essas cargas não foram muito elevadas em um deles e, por este motivo, os itens foram mantidos, sendo considerados nos fatores em que apresentaram a carga mais elevada.

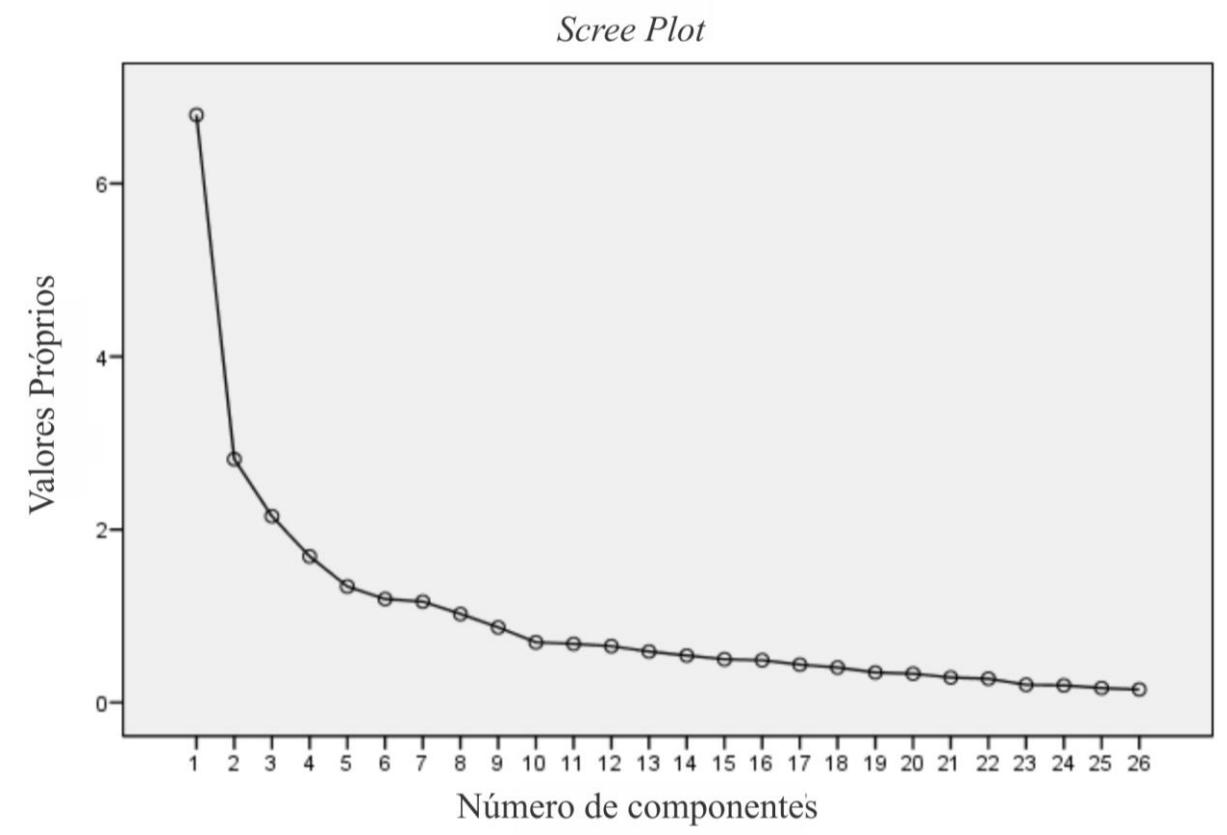

Figura 1. Scree plot da escala de estratégias de aprendizagem no trabalho

\section{Discussão}

A análise semântica dos itens em cada fator, que levou em consideração aqueles com as maiores cargas, evidenciou uma estrutura que corrobora a obtida na validação realizada por Brandão (2009). Naquele caso, o instrumento foi aplicado a pessoas ocupando posições de alta gerência na hierarquia das agências bancárias, o que pode explicar a semelhança entre esses resultados. A teoria acerca das estratégias de aprendizagem postula que estas são suscetíveis ao contexto individual de trabalho (Pantoja, 2004), o que pode explicar a semelhança nos resultados obtidos.

Do mesmo modo que com Brandão (2009), os itens relativos à reflexão extrínseca e reflexão intrínseca, propostos originalmente por Holman et al. (2001), agruparam-se em um único fator, aqui também denominado "Reflexão Intrínseca e Extrínseca". Indicam que, possivelmente, indivíduos ocupando funções de direção interpretam como semelhantes esses dois 
Tabela 4

Fatores, itens, indices de confiabilidade dos fatores e cargas fatoriais dos itens

\begin{tabular}{lccc}
\hline Itens & & \multicolumn{1}{c}{ Cargas fatoriais } \\
\hline & 1 & 2 & 3 \\
\hline Fator 1: reflexão intrínseca e extrínseca (alpha=0,88) & & \\
\hline $\begin{array}{l}22 \text { Tento compreender como as diferentes áreas de governo } \\
\text { influenciam o exercício de minha função. }\end{array}$ & 0,85 \\
$\begin{array}{l}23 \text { Tento conhecer como as diferentes áreas de governo estão } \\
\text { relacionadas entre si. }\end{array}$ & 0,83 \\
$\begin{array}{l}14 \text { Procuro compreender como o exercício da minha função está } \\
\text { relacionado com os resultados obtidos pelas várias áreas de governo. }\end{array}$ & 0,79 \\
$\begin{array}{l}17 \text { Ao exercer minha função, penso em como ela está relacionada } \\
\text { aos objetivos estratégicos de governo. }\end{array}$ & 0,65 & \\
$\begin{array}{l}15 \text { Procuro compreender como novos conhecimentos e informações } \\
\text { interferem na maneira como exercito minha função. }\end{array}$ & 0,52 \\
$\begin{array}{l}12 \text { Para melhorar o exercício da minha função, reflito sobre como } \\
\text { ela contribui para atender as expectativas da população do } \\
\text { município. }\end{array}$ & 0,50 & \\
\end{tabular}

Fator 2: busca de ajuda em material escrito (alpha=0,78)

08 Para exercer melhor minha função, consulto documentos e outros materiais que descrevem experiências implementadas em outros lugares.

07 Lendo livros e outros documentos, procuro adquirir novos conhecimentos.

09 Para melhorar o exercício da minha função, busco memorizar, normas, leis, instruções, pareceres jurídicos, etc.

19 Quando tenho dúvidas sobre algum tema, procuro ajuda em 0,83 publicações, informativos e relatórios sobre o assunto.

10 Para melhorar o exercício de minha função, procuro compreender $\quad 0,53$ melhor cada procedimento e tarefa.

26 Visando obter informações importantes para o exercício da $\quad 0,42$ minha função, consulto a internet.

Fator 3: busca de ajuda interpessoal (alpha $=0,82$ )

16 Procuro obter novos conhecimentos e informações conversando com outros dirigentes.

02 Converso com outros dirigentes mais experientes quando tenho dúvidas...

18 Quando tenho dúvidas sobre algum assunto, converso com membros de outras áreas de governo.

13 Converso com outros membros do governo quando necessito $\quad 0,41 \quad 0,53$ aprender algo sobre o exercício da minha função.

Fator 4: reprodução (alpha $=0,68)$

25 Visando exercer melhor minha função, busco repetir

20 Realizo as atividades relativas à minha função como se estivesse

0,60

no "piloto automático".

11 Para melhorar o exercício da minha função, procuro seguir sempre os mesmos procedimentos.

21 Realizo as atividades relativas à minha função sem refletir $\quad-0,31 \quad 0,38$ porque elas são necessárias.

Fator 5: aplicação prática (alpha $=0,65)$

06 Experimento, na prática, novas formas de exercer minha função

24 Testo novos conhecimentos aplicando-os na prática do exercício

0,31 da minha função.

01 Aprendo na prática, por tentativas sucessivas...

03 Critico o exercício da minha função tentando compreendê-lo 
tipos de reflexão, tendo em vista que o escopo de sua atuação, e consequentemente do seu aprendizado, já é o nível mais abrangente da organização na qual atuam.

O segundo fator, "busca de ajuda em material escrito", congregou os itens previstos para essa dimensão do construto, porém com o acréscimo de dois itens de outros fatores ("Reflexão Intrínseca" e "Reprodução", respectivamente): "10 - Para melhorar o exercício de minha função, procuro compreender melhor cada procedimento e tarefa" e "09 - Para melhorar o exercício da minha função, busco memorizar, normas, leis, instruções, pareceres jurídicos, etc". Os dois casos, provavelmente, se devem ao fato de que, para estes sujeitos, a compreensão dos procedimentos a serem adotados na execução das tarefas exige a consulta a normas e leis estabelecidas, todas necessariamente escritas.

Os demais fatores, "Busca de Ajuda Interpessoal", "Reprodução" e "Aplicação Prática", mantiveram as mesmas características do instrumento validado por Brandão (2009). Com isso, as descrições dos fatores se mantêm coerentes com a descrição das estratégias apresentadas na Tabela 1, a não ser pela junção das duas modalidades de reflexão. A escala validada conta com 24 itens, excluídos os dois itens que iniciavam com "não".

\section{Considerações finais}

A pesquisa relatada pretendeu contribuir para melhorar a compreensão acerca das estratégias de aprendizagem que os indivíduos utilizam no desempenho de suas atividades profissionais, especialmente no contexto atual, em que os indivíduos devem apresentar para lidar com as novas formas de organização do trabalho (Pantoja, 2004). A esse respeito, a coerência entre resultados obtidos nesse estudo e os de estudos anteriores aponta para a estabilidade da medida utilizada, a despeito das diferenças entre os contextos de trabalho e entre os papéis ocupacionais dos participantes.

Com base nesses resultados, passam a ter maior relevância os estudos acerca das relações entre as variáveis aqui mensuradas e outras relativas tanto ao próprio indivíduo quanto ao contexto de trabalho, como fatores que podem ajudar a desenvolver determinadas estratégias de aprendizagem, ou, ainda, a eventual influência das práticas de gestão sobre o uso dessas estratégias. Além disto, no futuro será preciso envidar esforços visando à validação de uma medida que inclua as estratégias autorregulatórias de aprendizagem, particularmente em contextos de trabalho efetivo, pois os resultados das pesquisas que incluem este subconjunto de estratégias foram obtidos em condições de treinamento (Zerbini \& Abbad, 2008). Finalmente, será preciso investigar mais amplamente os efeitos do uso das estratégias de aprendizagem no desenvolvimento de competências e em sua expressão no desempenho das pessoas no trabalho.

\section{Referências}

Abbad, G. S., \& Borges-Andrade, J. E. (2004). Aprendizagem humana em organizações e trabalho. In J. C. Zanelli, J. E. Borges-Andrade, \& A. V. B. Bastos (Orgs.), Psicologia, Organizações e Trabalho no Brasil (pp. 237275). Porto Alegre: Artmed.
Antonello, C. S. (2005). Articulação da aprendizagem formal e informal: seu impacto no desenvolvimento de competências gerenciais. Alcance, 12, 183-209.

*Beviláqua-Chaves, A. (2007). Estratégias de aprendizagem no trabalho em contexto de mudança organizacional (Dissertação de mestrado, Universidade de Brasília, Brasília).

Bierema, L. L., \& Eraut, M. (2004). Workplace-focused learning: perspective on continuing professional education and human resource development. Advances in Developing Human Resources, 6, 52-68.

*Brandão, H. P. (2009). Aprendizagem, contexto, competência e desempenho: um estudo multinivel (Tese de doutorado, Universidade de Brasília, Brasília).

*Carvalho-Silva, A. R. (2008). Clima social da organização, motivação e aprendizagem no trabalho (Dissertação de mestrado, Universidade de Brasília, Brasília).

Conlon, T. J. (2004). A review of informal learning literature, theory and implications for practice in developing global professional competence. Journal of European Industrial Training, 28, 283-295.

Eraut, M. (2004). Informal learning in the workplace. Studies in Continuing Education, 26, 247-73.

Frese, M. (2008). The changing nature of work. In N. Chmiel (Org.), An introduction to work and organizational psychology (pp. 397-413). Oxford: Blackwell.

Hair Jr., J. F., Anderson, R. E., Tatham, R. L., \& Black, W. C. (2005). Análise multivariada de dados. Porto Alegre: Bookman.

*Holman, D., Epitropaki, O., \& Fernie, S. (2001). Understanding learning strategies in the workplace: a factor analytic investigation. Journal of Occupational and Organizational Psychology, 74, 675-681.

Marsick, V. J., \& Volpe, M. (1999). The nature and need for informal learning. Advances in Developing Human Resources, 1, 1-9.

Matus, C. (1996). Adeus, senhor presidente: governantes governados. São Paulo: Fundap.

*Pantoja, M. J. (2004). Estratégias de aprendizagem no trabalho e percepções de suporte à aprendizagem contínua: uma análise multinivel (Tese de doutorado, Universidade de Brasília, Brasília).

*Ribeiro, R. L. (2005). Motivação para aprendizagem informal no trabalho: construção de medidas e investigação de modelo teórico (Dissertação de mestrado, Universidade de Brasília, Brasília).

Sonnentag, S., Niessen, C., \& Ohly, S. (2004). Learning at work: training and development. In C. L. Cooper, \& I. T. Robertson (Orgs.), International review of Industrial and Organizational Psychology: vol. 19. (pp. 249-289). London: John Wiley \& Sons.

Souza, C. (2009). Estratégias de aprendizagem e competências no trabalho (Dissertação de mestrado, Universidade de Brasília, Brasília).

Tynjälä, P. (2008). Perspectives into learning at the workplace. Educational Research Review, 3, 130-154.

Warr, P., \& Allan, C. (1998). Learning strategies and occupational training. International Review of Industrial and Organizational Psychology, 13, 84-121.

*Warr, P., \& Downing, J. (2000). Learning strategies, learning anxiety and knowledge acquisition. British Journal of Psychology, 91, 311-333.

*Zerbini, T. (2003). Estratégias de aprendizagem, reações aos procedimentos de um curso via Internet, reações ao tutor e impacto do treinamento no trabalho (Dissertação de mestrado, Universidade de Brasília, Brasília).

*Zerbini, T., \& Abbad, G. (2008). Estratégias de aprendizagem em curso a distância: validação de uma escala. Psico, 13(2), 177-187.

*Zerbini, T., Carvalho, R. S., \& Abbad, G. (2005). Treinamento a distancia via internet: construção e validação de escala de estratégias de aprendizagem. In Associação Nacional dos Programas de Pós-graduação em Administração (Org.), Anais do XXIX Encontro da Associação Nacional dos Programas de Pós-graduação em Administração. Texto completo (pp. 1-15). Brasília: Autor. 


\section{Apêndice}

Tabela A1

Estudos abordando construção e validação de medidas de estratégias de aprendizagem

\begin{tabular}{|c|c|c|}
\hline Autor & Amostra & Resultados \\
\hline $\begin{array}{l}\text { Warr e } \\
\text { Downing } \\
(2000)\end{array}$ & $\begin{array}{l}288 \text { participantes de curso } \\
\text { preparatório na área de } \\
\text { mecânica de automóveis } \\
190 \text { Estudantes universitários } \\
\text { de cursos de Artes e Ciências }\end{array}$ & $\begin{array}{l}\text { Análise Fatorial Exploratória: } \\
\text { Estrutura empírica composta de oito fatores: Repetição, } \\
\text { Reflexão Ativa, Busca de Ajuda Interpessoal, Busca de } \\
\text { Ajuda em Material Escrito, Controle Emocional, Controle } \\
\text { da Motivação e Monitoramento da Compreensão. Todos os } \\
\text { fatores apresentaram índices de confiabilidade razoáveis e } \\
\text { bons que variaram de } 0,73 \text { a } 0,90 \text {. }\end{array}$ \\
\hline $\begin{array}{l}\text { Holman et } \\
\text { al. } \\
(2001)\end{array}$ & $\begin{array}{l}\text { Amostra Total: } 628 \text { técnicos } \\
\text { de call center } \\
\text { Foi realizada validação } \\
\text { cruzada considerando, para a } \\
\text { análise exploratória, uma } \\
\text { amostra de } 399 \text { e, depois, para } \\
\text { a análise confirmatória, uma } \\
\text { amostra de } 319 \text { profissionais. }\end{array}$ & $\begin{array}{l}\text { Análise Fatorial Exploratória: } \\
\text { Estrutura empírica composta de seis fatores: Reprodução, } \\
\text { Reflexão Intrínseca, Reflexão Extrínseca, Busca de Ajuda } \\
\text { Interpessoal, Busca de Ajuda em Material Escrito e } \\
\text { Aplicação Prática. Os fatores apresentaram índices de } \\
\text { confiabilidade razoáveis e bons, variando de } 0,72 \text { a } 0,82 \\
\text { Análise Fatorial Confirmatória: } \\
\text { Os seis fatores de primeira ordem foram explicados por } \\
\text { dois constructos latentes denominados estratégias } \\
\text { cognitivas e comportamentais.- Qui-quadrado }(182, \mathrm{n} \\
=319)=365.73, \mathrm{NNFI}=0.94, \mathrm{CFI}=, 95, \mathrm{RMSEA}=0,06 \text {. }\end{array}$ \\
\hline $\begin{array}{l}\text { Pantoja } \\
(2004)\end{array}$ & $\begin{array}{l}380 \text { profissionais de } \\
\text { organizações que atuavam em } \\
\text { diferentes segmentos: } \\
\text { telecomunicações, hotelaria, } \\
\text { energia elétrica e mobiliário } \\
\text { e financeiro. }\end{array}$ & $\begin{array}{l}\text { Análise Fatorial Exploratória } \\
\text { Estrutura empírica composta de seis fatores: Reprodução, } \\
\text { Reflexão Intrínseca, Reflexão Extrínseca, Busca de Ajuda } \\
\text { Interpessoal, Busca de Ajuda em Material Escrito e } \\
\text { Aplicação Prática. Todos os fatores apresentaram índices } \\
\text { de confiabilidade razoáveis e bons que variaram de } 0.65 \text { a } \\
0,86 \text {. }\end{array}$ \\
\hline $\begin{array}{l}\text { Zerbini } \\
(2003)\end{array}$ & $\begin{array}{l}1.860 \text { gestores de pequenas e } \\
\text { médias empresas }\end{array}$ & $\begin{array}{l}\text { Análise Fatorial Exploratória } \\
\text { Estrutura fatorial composta de três fatores: Busca de Ajuda } \\
\text { Interpessoal, Elaboração e Aplicação prática, Reprodução, } \\
\text { Organização e Busca de Ajuda em Material Escrito. Os } \\
\text { índices de confiabilidade variaram de } 0,75 \text { a } 0,85 \text {. }\end{array}$ \\
\hline $\begin{array}{l}\text { Pantoja } \\
(2004)\end{array}$ & $\begin{array}{l}906 \text { profissionais de } \\
\text { diferentes áreas e níveis de } \\
\text { atuação }\end{array}$ & $\begin{array}{l}\text { Análise fatorial exploratória: } \\
\text { Estrutura fatorial composta de } 5 \text { fatores: Busca de Ajuda } \\
\text { em Material Escrito, Reprodução, Busca de Ajuda } \\
\text { Interpessoal, Reflexão Extrínseca, Aplicação Prática e } \\
\text { Reflexão Intrínseca. Índices de confiabilidade variaram } \\
\text { entre } 0,80 \text { e } 0,87 \text {. }\end{array}$ \\
\hline $\begin{array}{l}\text { Ribeiro } \\
(2005)\end{array}$ & $\begin{array}{l}\text { Total de } 1007 \text { alunos de pós- } \\
\text { graduação, de diferentes áreas } \\
\text { de atuação, formação } \\
\text { acadêmica e cargos, } \\
\text { utilizando duas sub-amostras } \\
\text { em validação cruzada }\end{array}$ & $\begin{array}{l}\text { Análise fatorial confirmatória: } \\
\text { Estrutura fatorial composta de } 1 \text { fator geral primário } \\
\text { contendo e } 5 \text { fatores de segunda ordem: Busca de Ajuda } \\
\text { em Material Escrito, Busca de Ajuda Interpessoal, } \\
\text { Reflexão Extrínseca, Aplicação Prática e Reflexão } \\
\text { Intrínseca. } \\
\text { Índices de confiabilidade variaram entre } 0,76 \text { e } 0,87 \text {. }\end{array}$ \\
\hline $\begin{array}{l}\text { Zerbini, } \\
\text { Carvalho e } \\
\text { Abbad } \\
(2005)\end{array}$ & $\begin{array}{l}1860 \text { participantes de curso } \\
\text { técnico a distância }\end{array}$ & $\begin{array}{l}\text { Análise fatorial exploratória: } \\
\text { Estrutura fatorial composta de } 3 \text { fatores: Busca de Ajuda } \\
\text { Interpessoal; Elaboração e Aplicação Prática do Conteúdo; } \\
\text { e Repetição, Organização e Ajuda do Material. Índices de } \\
\text { confiabilidade variaram entre } 0,75 \text { e } 0,85 \text {. }\end{array}$ \\
\hline $\begin{array}{l}\text { Bevilácqua- } \\
\text { Chaves } \\
(2007)\end{array}$ & $\begin{array}{l}467 \text { servidores de } 4 \\
\text { organizações públicas }\end{array}$ & $\begin{array}{l}\text { Análise fatorial confirmatória: } \\
\text { Estrutura fatorial composta de } 5 \text { fatores: Busca de Ajuda } \\
\text { em Material Escrito, Reprodução, Busca de Ajuda } \\
\text { Interpessoal, Reflexão Extrínseca, Aplicação Prática e } \\
\text { Reflexão Intrínseca. Índices de confiabilidade variaram } \\
\text { entre } 0,78 \text { e } 0,81 \text {. }\end{array}$ \\
\hline
\end{tabular}




\begin{tabular}{|c|c|c|}
\hline Autor & Amostra & Resultados \\
\hline $\begin{array}{l}\text { Zerbini e } \\
\text { Abbad } \\
(2008)\end{array}$ & $\begin{array}{l}993 \text { participantes de curso } \\
\text { técnico a distância }\end{array}$ & $\begin{array}{l}\text { Análise fatorial exploratória: } \\
\text { Estrutura fatorial composta de } 7 \text { fatores: Controle da } \\
\text { Emoção; Busca de Ajuda Interpessoal; Repetição e } \\
\text { Organização; Controle da Motivação; Elaboração; Busca } \\
\text { de Ajuda ao Material Didático; Monitoramento da } \\
\text { Compreensão. Índices de confiabilidade variaram entre } \\
0,75 \text { e } 0,89 \text {. }\end{array}$ \\
\hline $\begin{array}{l}\text { Carvalho- } \\
\text { Silva (2008) }\end{array}$ & $\begin{array}{l}394 \text { sujeitos entre } \\
\text { funcionários de uma empresa } \\
\text { pública federal e servidores } \\
\text { de um órgão da administração } \\
\text { direta federal }\end{array}$ & $\begin{array}{l}\text { Análise Fatorial Exploratória: } \\
\text { Estrutura empírica composta de seis fatores: Busca de } \\
\text { Ajuda Interpessoal e em Material Escrito, Reflexão } \\
\text { Extrínseca, Reprodução, Reflexão Intrínseca/ Aplicação } \\
\text { Prática. Os fatores apresentaram índices de confiabilidade } \\
\text { razoáveis e bons, variando de } 0,73 \text { a } 0,88 \text {. } \\
\text { Análise Fatorial Confirmatória: } \\
\text { Os cinco fatores de primeira ordem foram explicados por } \\
\text { um constructo latente denominado Estratégias Gerais de } \\
\text { Aprendizagem no Trabalho. Qui-quadrado = } 0,80 \text { com } \\
\text { cargas fatoriais variando de } 0,55 \text { a } 0,88 \text {. }\end{array}$ \\
\hline $\begin{array}{l}\text { Brandão } \\
(2009)\end{array}$ & $\begin{array}{l}\text { Análise fatorial exploratória: } \\
311 \text { gestores de instituição } \\
\text { bancária } \\
\text { Análise fatorial confirmatória: } \\
926 \text { gestores de instituição } \\
\text { bancária }\end{array}$ & $\begin{array}{l}\text { Análise fatorial exploratória: } \\
\text { Estrutura fatorial composta de } 6 \text { fatores: Reflexão } \\
\text { Intrínseca e Reflexão Extrínseca, Busca de Ajuda } \\
\text { Interpessoal, Busca de Ajuda em Material Escrito e } \\
\text { Aplicação Prática, Reprodução a, reprodução b. Índices de } \\
\text { confiabilidade superiores a 0,70. } \\
\text { Análise fatorial confirmatória: } \\
\text { Estrutura fatorial composta de } 5 \text { fatores: Reflexão } \\
\text { Intrínseca e Reflexão Extrínseca, Busca de Ajuda } \\
\text { Interpessoal, Busca de Ajuda em Material Escrito e } \\
\text { Aplicação Prática, Reprodução. Índice de confiabilidade } \\
\text { variando de } 0,79 \text { a } 0,92 \text {. }\end{array}$ \\
\hline
\end{tabular}

Adaptado de Pantoja (2004) e expandido a partir deste ano. 
334 V. V. Moraes \& J. E. Borges-Andrade

Valéria Vieira de Moraes, doutora em Aprendizagem nas Organizações pela Universidade de Brasília, é técnica em assuntos educacionais na Escola Nacional de Administração Pública. Endereço para correspondência: Escola Nacional de Administração Pública- Cordenadoria Geral de Projetos de Capacitação, SAIS Área 2A - Brasília - DF. CEP: 70610-900. Telefone: (61) 81223120/ fax (61) 20203179. E-mail: moraes.valeria@ gmail.com

Jairo Eduardo Borges-Andrade, Ph.D. em Sistemas Instrucionais pela Florida State University, FSU, é professor titular da Universidade de Brasília. E-mail: jairo.borges@gmail.com 